\title{
Automatic mapping of lunar landforms using DEM-derived geomorphometric parameters
}

\author{
WANG Jiao ${ }^{1,2},{ }^{*}$ CHENG Weiming ${ }^{2}$, ZHOU Chenghu ${ }^{2}$, ZHENG Xinqi ${ }^{1}$ \\ 1. School of Information Engineering, China University of Geosciences, Beijing 100083, China; \\ 2. State Key Laboratory of Resources and Environmental Information System, Institute of Geographic Sciences \\ and Natural Resources Research, CAS, Beijing 100101, China
}

\begin{abstract}
Developing approaches to automate the analysis of the massive amounts of data sent back from the Moon will generate significant benefits for the field of lunar geomorphology. In this paper, we outline an automated method for mapping lunar landforms that is based on digital terrain analysis. An iterative self-organizing (ISO) cluster unsupervised classification enables the automatic mapping of landforms via a series of input raster bands that utilize six geomorphometric parameters. These parameters divide landforms into a number of spatially extended, topographically homogeneous segments that exhibit similar terrain attributes and neighborhood properties. To illustrate the applicability of our approach, we apply it to three representative test sites on the Moon, automatically presenting our results as a thematic landform map. We also quantitatively evaluated this approach using a series of confusion matrices, achieving overall accuracies as high as $83.34 \%$ and Kappa coefficients $(\mathrm{K})$ as high as 0.77 . An immediate version of our algorithm can also be applied for automatically mapping large-scale lunar landforms and for the quantitative comparison of lunar surface morphologies.
\end{abstract}

Keywords: automatic classification; geomorphometric parameters; ISO cluster; lunar landforms; DEM

\section{Introduction}

Landforms are the result of geologic and geomorphologic processes that occur on the surface of the Earth and other planets (Bolongaro-Crevenna et al., 2005). Accurately collecting and processing information about landforms is necessary for landscape evaluation, hazard prediction, suitability and erosion studies, as well as various landscape and regional planning (Drăguţ and Blaschke, 2006). Consequently, mapping landforms on the surfaces of planets at broad spatial scales is becoming increasingly important; easily accessible digital elevation model (DEM) data has led to the development of a growing number of automated landform mapping techniques that utilize remote sensing (RS) and geographic information system (GIS) approaches (Butle and Walsh, 1998; Florinsky, 1998; Ehlers et al., 2002).

Received: 2017-06-13 Accepted: 2017-07-31

Foundation: National Natural Science Foundation of China, No.41571388; National Special Basic Research Fund, No.2015FY210500

Author: Wang Jiao (1990-), PhD, specialized in planetary geomorphology and spatial analysis. E-mail: wjiao@lreis.ac.cn

*Corresponding author: Cheng Weiming (1973-), Professor, E-mail: chengwm@1reis.ac.cn 
One pixel in a DEM encapsulates an elevation value vector as well as other extractable measures that relate to basic components of terrain, including slope, aspect, convexity, and relief amplitude. It is also expected to be the case that pixels constituting a particular landform will encapsulate similar terrain vectors; these vectors are considered to be similar if the Euclidean distance between them is small (Giles and Franklin, 1998; Miliaresis, 2001; Bue and Stepinski, 2006). Thus, landform classification can be achieved by applying a clustering algorithm across all attribute vectors to determine their exclusive similarity at a given site. Enabling these comparisons is the true value of a DEM and the essence of the classification method.

A range of manual methods was used in the past to classify macro-morphologic landforms from contour maps or stereo aerial photographs. However, as these approaches are relatively time-consuming and generate results that depend on subjective decisions made by the interpreter, they are less suitable for the efficient analysis of large datasets. Thus, a series of automated methods has been developed to identify individual terrain features; physical characteristics can be extracted from a DEM using a variety of methods including the combination of morphometric parameters like slope gradient, local convexity, and surface texture (Iwahashi and Pike, 2007), as well as fuzzy logic and unsupervised classification (Burrough et al., 2000; Adediran et al., 2004), supervised classification (Hengl and Rossiter, 2003; Prima et al., 2006), probabilistic clustering algorithms (Stepinski and Collier, 2004; Stepinski and Vilalta, 2005), multivariate descriptive statistics (Dehn et al., 2001), and double ternary diagram classification (Bolongaro-Crevenna et al., 2005). Although these methods have been applied to data from other planets, including Mars (Stepinski and Collier, 2004) and the Moon (Wang et al., 2015), they are too specific in the context of their respective fields of application to be successfully adapted for landscape classification over broad spatial scales. In addition, most of these applications are unable to adequately evaluate the characteristics of lunar landforms even though digital computers and GIS methods have removed many of the obstacles inherent to terrain classification based on surface geometry for areas of any size or suitable spatial resolution. We therefore present a method for the automatic classification of morphologic landforms that is based on a DEM within a GIS environment. We utilize ISO cluster unsupervised classification for landform mapping on the Moon based on a series of input raster bands that define six morphologic parameters. We use ISO clustering to automatically classify morphometric features into a series of classes, and assemble the morphometric parameters derived from a DEM to characterize landforms. We discuss the limitations inherent to the use of this automatic classification, and extend this DEM-based approach to map other Moon-like landforms.

\section{Study area and data}

The United States Geological Survey (USGS) lunar geologic mapping program divides the Moon into 30 quadrangles (Gaddis et al., 2006). To test our algorithm, we selected three test areas based on these data that include different landforms; thus, LQ-8 is a representative cratered highland area, LQ-11 is a mare region primarily covered with basaltic lava flows, while LQ-20 includes both mare plains and highlands. Each of our sites is almost $10^{5} \mathrm{~km}^{2}$ in size (Figure 1); a DEM for each was constructed using the lunar orbiter laser altimeter (LOLA), an instrument mounted on the NASA lunar reconnaissance orbiter spacecraft. More than 6.5 billion LOLA measurements were converted into a DEM (Smith et al., 2010) using 
generic mapping tools software (Wessel and Smith 2001) at a resolution of 256 pixels per degree. In the Mercator projection, each of these pixels is $118 \mathrm{~m}$ in size at the equator; we used the USGS lunar geologic map that includes landform classification attributes as a reference to test our algorithm.

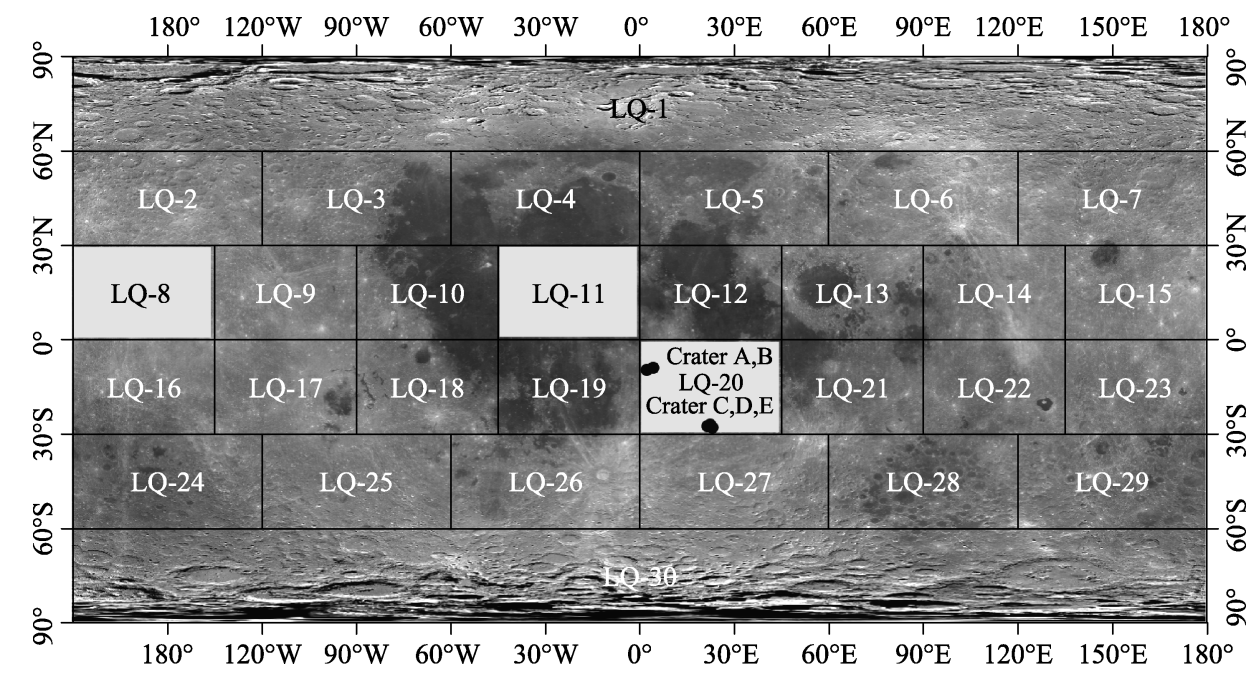

Figure 1 Map showing the locations of our study areas as well as the positions of selected craters

\section{Methods}

The classification algorithm used in this study includes DEM preprocessing, morphologic parameterization, ISO cluster unsupervised classification, and final landform map (Figure 2). Module implementation was designed to take advantage of publically available software packages in ArcGIS.

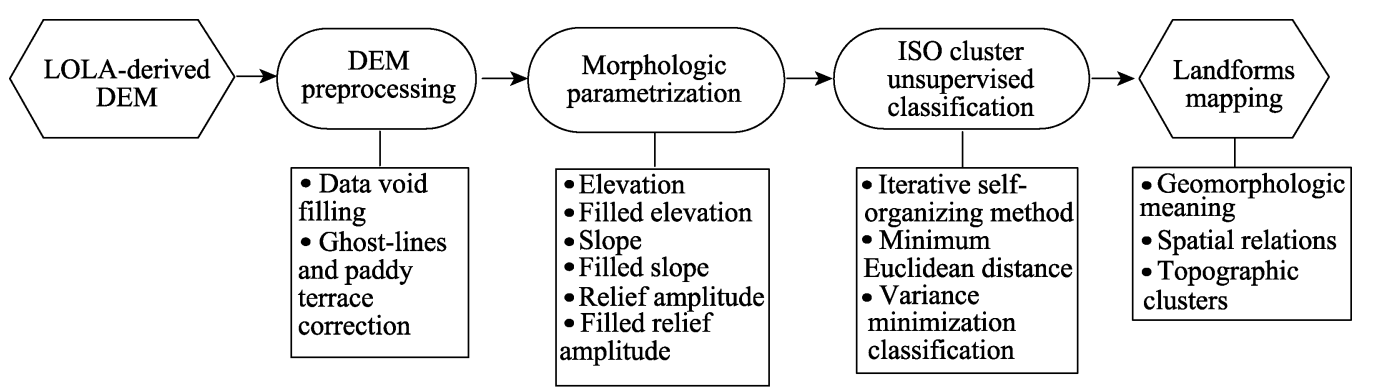

Figure 2 Flow chart illustrating the computational landform classification process applied in this study

\subsection{DEM preprocessing}

A DEM usually contains errors that need to be minimized before it can be utilized to extract terrain parameters. Thus, to mitigate external inputs, we corrected the DEM used in this study by lowering the elevation values of pixels around the model edges to correspond with the lowest recorded value for elevation (Tarboton et al., 1989) and completed the filling progress to address the issue of craters. We used the difference between filled and original elevation grids with non-zero values to represent pixels located within craters (O'Callaghan and Mark, 1984); the filled elevation process was completed using the sink, watershed, zonal 
statistics, zonal fill, and minus geoprocessing tools in the software program ArcGIS. Finally, because topographic analysis requires that a DEM is in a metric projection system, we converted GCS_MOON_2000 geographic coordinates to the Mercator projection.

\subsection{Morphologic parameterization}

In order to account for dichotomies (i.e., highlands and mares) and widely distributed impact craters on the surface of the Moon in our classification, we used six morphologic parameters (i.e., elevation, filled elevation, slope, filled slope, relief amplitude, and filled relief amplitude) to describe terrains derived from original and filled elevation fields. We initially derived slope and relief amplitude from the corrected DEM, and applied several algorithms to calculate topographic features. Because the results from different algorithms are closely correlated (Guth, 1995; Hodgson, 1998; Jones, 1998), we applied the formula proposed by Burrough and McDonnell (2011) to calculate slope and relief amplitude. Thus, filled slope and relief amplitude were calculated using the filled elevation field. However, because attributes stored in the different layers of our digital topography model (DTM) have different physical meanings and value ranges, we normalized original attribute values to a $(0,1)$ range so that all variables contribute equally to distances between different pixels. Note that a DEM is simply one kind of DTM in which layers encapsulate elevation values.

\subsection{ISO cluster unsupervised classification}

Unsupervised classifications utilize naturally occurring statistical groupings in data to determine clusters. We applied this approach to a series of input raster bands using ISO cluster and maximum likelihood classification tools (Kohonen, 1982). The ISO cluster algorithm is an iterative, self-organizing process for computing minimum Euclidean distance when assigning each candidate cell to a cluster. The process is initiated arbitrarily by the software in the case of each cluster, and every cell is assigned to the closest mean distance within the multidimensional attribute space. New means are then recalculated for each cluster based on the attributes of cells that belong to each after the first iteration, before the process is then repeated; each cell is again assigned to the closest mean within the multidimensional attribute space, and new means are calculated for each cluster based on the membership of cells from each iteration. As the number of iterations is a free parameter, we experimented with $N$ $=12, N=15, N=20$, and $N=40$ clusters. Results show that clusters classify and display landforms at a level reasonably consistent with visual interpretation when $N=20$, and that clusters merge with their neighbors when statistical values are similar after stability is reached. We used the Jenks natural breaks algorithm (Jenks and Caspall, 1971) to perform final merging; in this variance-minimization classification, within class variance is as small as possible while between class variance is as large as possible.

\subsection{Landform mapping and interpretation}

We automated the final result of our classification as a thematic landform map; assigning colors to different clusters enables the classification to be clearly visualized. Because initial cluster results are numerals that lack geomorphologic meaning, we replaced these labels with semantic ones by reviewing the statistical properties of the topographic characteristic in each cluster and studying the spatial relationships between clusters. This enabled us to de- 
termine which clusters correspond to specific landform classes as well as to compute and apply shaded relief to images for visualization purposes.

\subsection{Confusion matrix}

To determine the accuracy of our algorithm, we tested the result of each classification against a reference map (Fortezzo and Hare, 2013) using a confusion matrix. This kind of matrix is appropriate for use with traditional classification methods as it assumes that pixels at reference locations can be assigned to single classes; thus, accuracy measures based on the proportion of correctly classified area can be calculated via the number of correctly classified pixels (Lewis and Brown, 2001). The result of each classification and the reference map were converted to grid files of the same resolution and pixels were classified as either 'crater', 'mare', 'lowland', 'highrelief', or 'highland'. These pixel classes were then assigned values of $0,10,20,30$, and 40 on the reference map and corresponding values of 0,1 , 2, 3, and 4 on the classification map. The two maps of the three test areas were then summed and a confusion matrix map constructed that comprised pixels with values ranging between 0 and 33. We then calculated overall accuracy (OA), producer accuracy (PA), user accuracy (UA), and the Kappa coefficient (K) based on values within the confusion matrix. Of these, OA measures the proportion of correctly classified reference pixels, while PA estimates the probability that a pixel of class $i$ has been correctly assigned within the reference classification, UA refers to the probability that a pixel assigned to class $i$ is actually a member of that group, and $\mathrm{K}$ measures the agreement between two classifications taking into account the possibility that coincidence can occur by chance (Cohen, 1960). Thus:

$$
\begin{gathered}
\mathrm{OA}=\sum_{k=1}^{n} a_{k k} / \sum_{i, k=1}^{n} a_{i k} \\
P A=a_{i i} / \sum_{i=1}^{n} a_{k i} \\
U A=a_{i i} / \sum_{i=1}^{n} a_{i k} \\
K=p_{o}-p_{e} / 1-p_{e}
\end{gathered}
$$

where $n$ denotes the total number of reference pixels, $k$ refers to the column, $i$ refers to the row, $p_{o}$ denotes relative observed agreement, and $p_{e}$ is the hypothetical probability of chance agreement. We computed confusion matrices and associated statistics using the software program ArcGIS 10.

\section{Results}

The values of topographic attributes averaged over pixels within each landform class for the three test areas are shown in Tables 1, 2, and 3. Average values where then used to construct a dendrogram of landform classes (Figure 3) that summarizes their degree of similarity. In these diagrams, classes that are more similar to one another are more closely connected; thus, Figure 3a shows that, of all possible pairs, class 2 and class 3 are most similar to one another, and also indicates that all 20 classes can be divided naturally into four larger groups which 
correspond to major landform types, $\mathrm{A}=(1,2,3,4,5,6,7,8), \mathrm{B}=(9,10,11,12,13), \mathrm{C}=$ $(14,15,16)$, and $\mathrm{D}=(17,18,19,20)$. A thematic map constructed on the basis of this landform classification is shown in Figure 4. The different colors on this map denote pixel class membership; a physical interpretation was applied by reviewing the statistical and topographic attributes of pixels comprising each class and by studying their spatial relationships. The legends to Figures 4-6 summarize our interpretations; our results divide the 20 landform classes into five larger groups, encompassing mares, craters, lowlands, areas of highrelief, and highlands. This manual division, which also takes spatial relationships into account, closely corresponds with the algorithmic grouping shown in Figure 3 based only on the Euclidean distances between average attribute vectors.

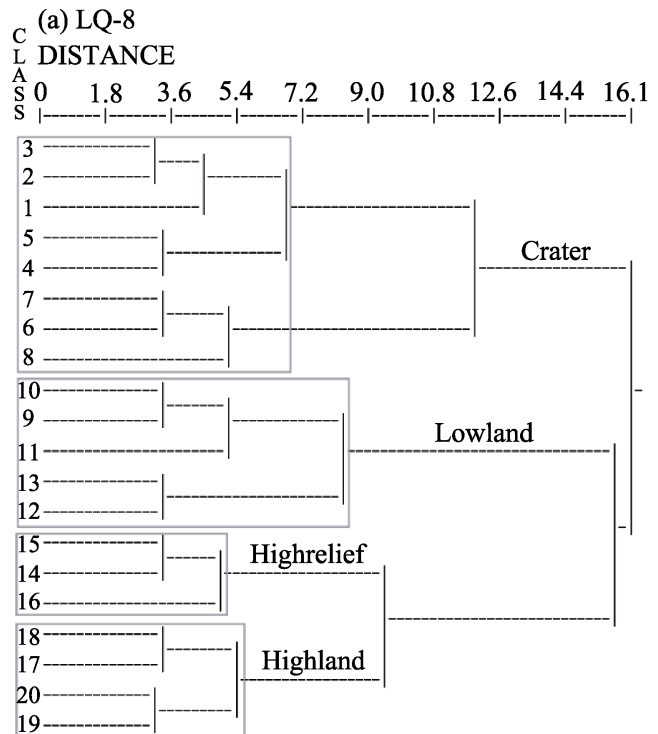

(b) LQ-11

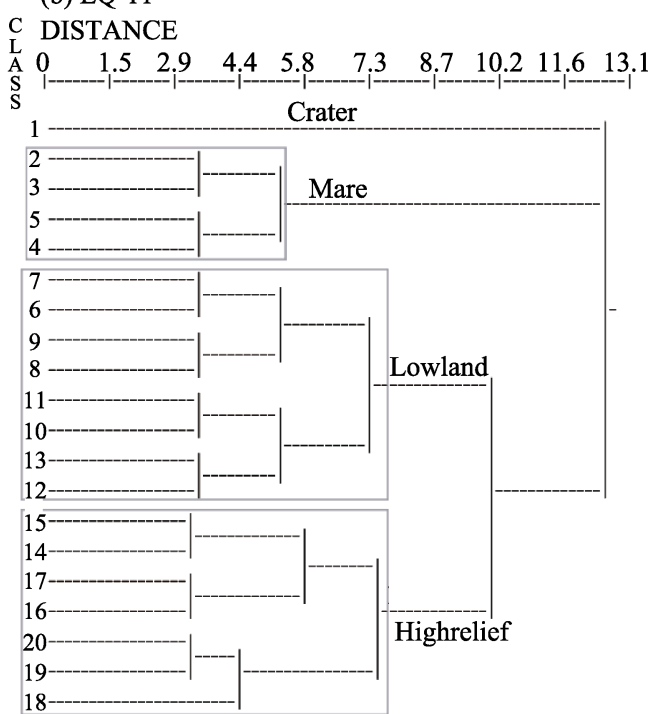

(c) LQ-20

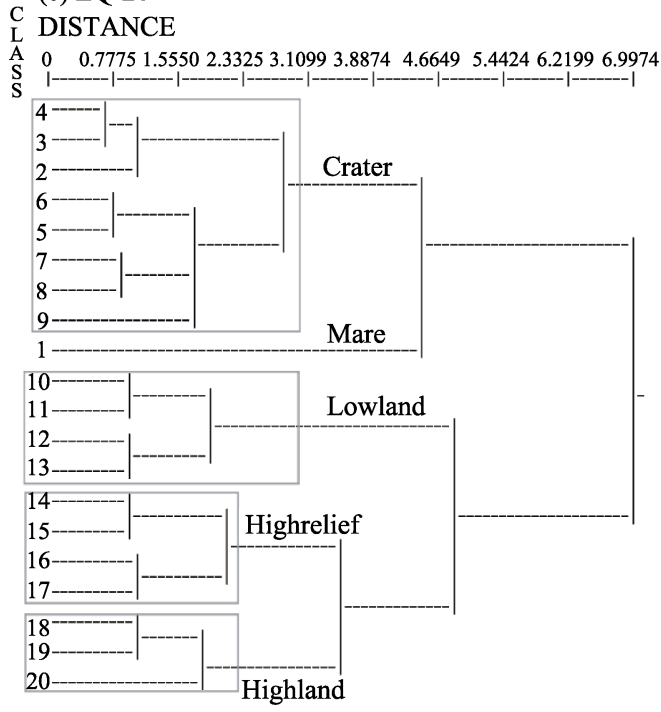

Figure 3 Dendrogram showing the relationships between the 20 landform classes generated by automatic classification within the LQ-8, LQ-11, and LQ-20 test areas. The gray rectangles denote the five major landform types identified manually by assigning geomorphologic interpretations to classes, while the multidimensional distance along the top of the dendrogram is the distance between classes in attribute space. 


\subsection{LQ-8}

Test area LQ-8 consists of cratered highlands that are not covered with basaltic lava. Results show that the topographic attributes of pixels in classes $1,2,3,4,5,6,7$, and 8 are similar, with the exception that the signatures of large values for filled elevation that subdivide this range of topography comprise four distinct groups. Thus, pixels classified within classes 5 and 6 have higher slope values, perhaps the result of steeper inner crater walls, while pixels classified within classes 7 and 8 have the highest values of all for filled slope and relief, perhaps because the crater rim in these cases is elevated with respect to the adjacent lowland. As all these classes are identified as flat floors inside craters, crater walls, and crater rims, we classify them all together in this study within a larger group which we refer to as 'craters'. Results show that $38.44 \%$ of pixels inside the LQ- 8 test area can be classified within this group and that the major feature discriminating classes of craters are their values for filled elevation (Table 1).

The common characteristic of pixels in classes $9,10,11,12$, and 13 is their low relief; as all these pixels are spatially located below the escarpment, we collected them together into a larger group which we refer to as 'lowland'. Results show that $24.21 \%$ of pixels within the LQ-8 test area can be classified within this group.

The pixels in classes 14,15 , and 16 are all located on highland at elevations in the vicinity of the escarpment; the common feature of all these pixels is a relatively similar slope value. Because the pixels in these groups collectively comprise an inter-crater plateau at relatively

Table 1 Average values for landform class morphologic parameters within the LQ-8 test area

\begin{tabular}{|c|c|c|c|c|c|c|c|}
\hline Class & $\begin{array}{c}\text { Count } \\
\text { (pixels) }\end{array}$ & $\begin{array}{c}\text { Elevation } \\
(\mathrm{m})\end{array}$ & $\begin{array}{c}\text { Filled } \\
\text { elevation }(\mathrm{m})\end{array}$ & $\begin{array}{c}\text { Slope } \\
\text { (degree) }\end{array}$ & $\begin{array}{c}\text { Filled } \\
\text { slope (degree) }\end{array}$ & $\begin{array}{l}\text { Relief } \\
(\mathrm{m})\end{array}$ & $\begin{array}{c}\text { Filled relief } \\
\text { (m) }\end{array}$ \\
\hline 1 & 106,694 & -697 & 5787 & 6.17 & 6.17 & 1188 & 1187 \\
\hline 2 & 262,266 & 512 & 4579 & 6.54 & 6.54 & 1245 & 1244 \\
\hline 3 & 304,078 & 1216 & 3877 & 6.58 & 6.6 & 1262 & 1261 \\
\hline 4 & 288,478 & 1794 & 3301 & 6.63 & 6.63 & 1263 & 1262 \\
\hline 5 & 249,714 & 2257 & 2839 & 6.67 & 6.67 & 1270 & 1272 \\
\hline 6 & 239,441 & 2618 & 2482 & 6.75 & 6.74 & 1272 & 1273 \\
\hline 7 & 229,001 & 2890 & 2215 & 6.78 & 6.79 & 1275 & 1276 \\
\hline 8 & 229,510 & 3112 & 2004 & 6.8 & 6.8 & 1278 & 1278 \\
\hline 9 & 222,440 & 3306 & 1796 & 6.9 & 6.9 & 1291 & 1291 \\
\hline 10 & 238,691 & 3491 & 1608 & 6.98 & 6.99 & 1297 & 1297 \\
\hline 11 & 253,876 & 3676 & 1423 & 6.99 & 6.99 & 1306 & 1306 \\
\hline 12 & 258,172 & 3864 & 1237 & 7.00 & 7.00 & 1314 & 1313 \\
\hline 13 & 261,774 & 4062 & 1040 & 7.02 & 7.02 & 1318 & 1318 \\
\hline 14 & 263,442 & 4281 & 821 & 7.03 & 7.03 & 1325 & 1325 \\
\hline 15 & 281,458 & 4539 & 562 & 7.03 & 7.03 & 1325 & 1325 \\
\hline 16 & 308,016 & 4864 & 235 & 7.04 & 7.04 & 1336 & 1336 \\
\hline 17 & 325,804 & 5280 & -182 & 7.24 & 7.25 & 1346 & 1346 \\
\hline 18 & 316,858 & 5823 & -723 & 7.31 & 7.32 & 1396 & 1395 \\
\hline 19 & 224,284 & 6548 & -1443 & 7.55 & 7.55 & 1412 & 1414 \\
\hline 20 & 102,783 & 7743 & -2634 & 7.74 & 7.75 & 1472 & 1472 \\
\hline
\end{tabular}


high elevations, we refer to them as 'highrelief'. Results show that $17.17 \%$ of pixels inside the LQ-8 test area can be classified within this group.

The pixels in classes 17, 18, 19, and 20 all exhibit negative filled elevation values as well as higher values of slope, relief, and filled attributes. The pixels in these three classes are spatially located on highland, above the escarpment, and fill in the space between craters. These highland classes are mainly differentiated from one another by their filled elevation values; results show that $19.52 \%$ of pixels inside the LQ- 8 test area can be classified as 'highland' (Figure 4).

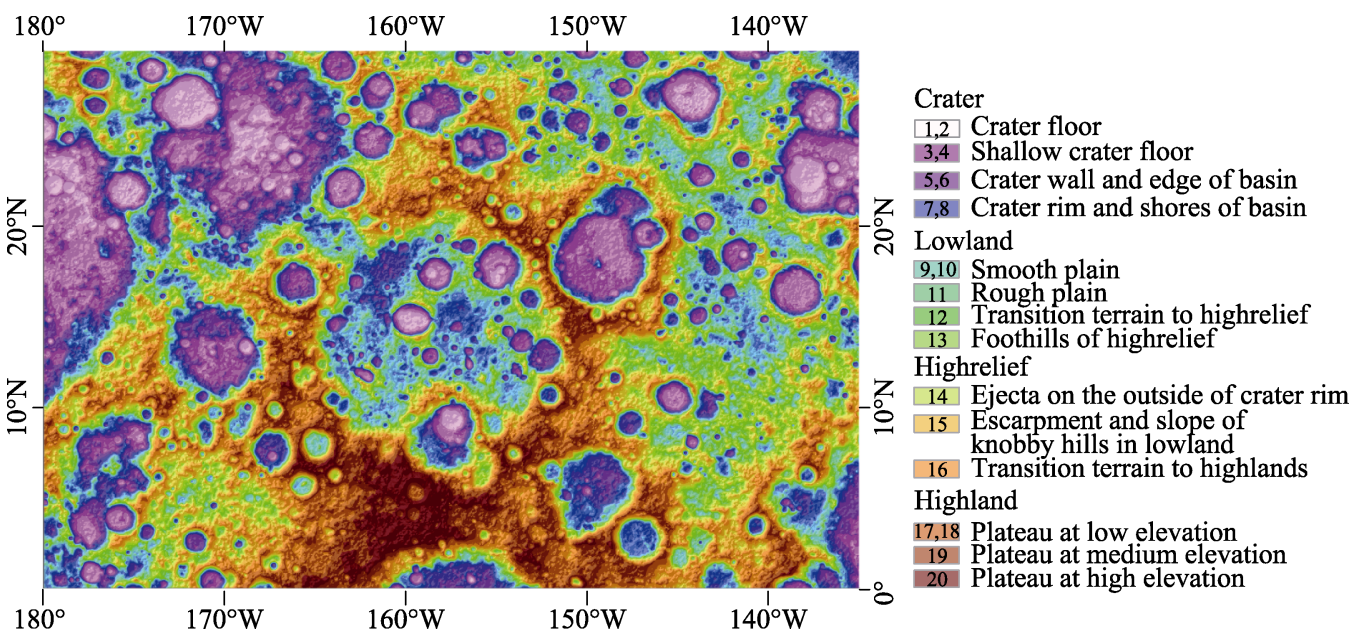

Figure 4 Thematic map showing automatically identified landforms within the LQ- 8 test area. The geographic categories corresponding with numbered landform classes are outlined in the legend

\subsection{LQ-11}

The LQ-11 test area mainly comprises basaltic lava flows containing a few craters. The topographic attributes for pixels in class 1 within this area are unique because they exhibit the smallest values; pixels in this class are spatially located within concave pits that are separately distributed, filling their inner spaces. Because the spatial distribution of these class 1 pixels forms a number of hotspots, we collectively refer to them as 'craters'; results show that just $0.86 \%$ of pixels inside the LQ-11 test area can be classified within this group (Table 2).

The topographic attributes of pixels in classes 2, 3, 4, and 5 encompass a similar range as their elevation values range between $-2800 \mathrm{~m}$ and $-2000 \mathrm{~m}$, their filled elevation values are all larger than $7200 \mathrm{~m}$, their slopes are less than 1.95, and their relief values are all less than $350 \mathrm{~m}$. The pixels in this class are spatially located in large and deep basins, and infill the inner space within basins which are often large, dark, basaltic plains formed by ancient volcanic eruptions. These pixels all correspond to a common landform type which we collectively refer to as 'mare'. Results show that $23.49 \%$ of pixels inside the LQ-11 test area can be classified within this group (Figure 5).

The geomorphometric values of pixels within the range encompassed by class 6 to class 13 are slightly larger than those of the mare group and vary over smaller intervals. These pixels are all spatially located below the escarpment and represent the transitional zone between mare plains and regions of high slope and relief. These pixels are therefore collectively referred to as 'lowland'; results show that $38.08 \%$ of pixels inside the LQ-11 test area 
can be classified within this group.

The pixels within the range encompassed by class 14 to class 20 are all located on highlands at high elevations in the vicinity of the escarpment. The pixels in these seven classes all share relatively high values of both slope and relief that vary over large intervals; taken together, they are indicative of an inter-mare plateau located on relatively highland while some represent ejecta on the outside of the crater rim. These pixels are collectively referred to as 'highrelief'; results show that $37.57 \%$ of pixels inside the LQ-11 test area can be classified within this group.

Table 2 Average values for landform class morphologic parameters within the LQ-11 test area

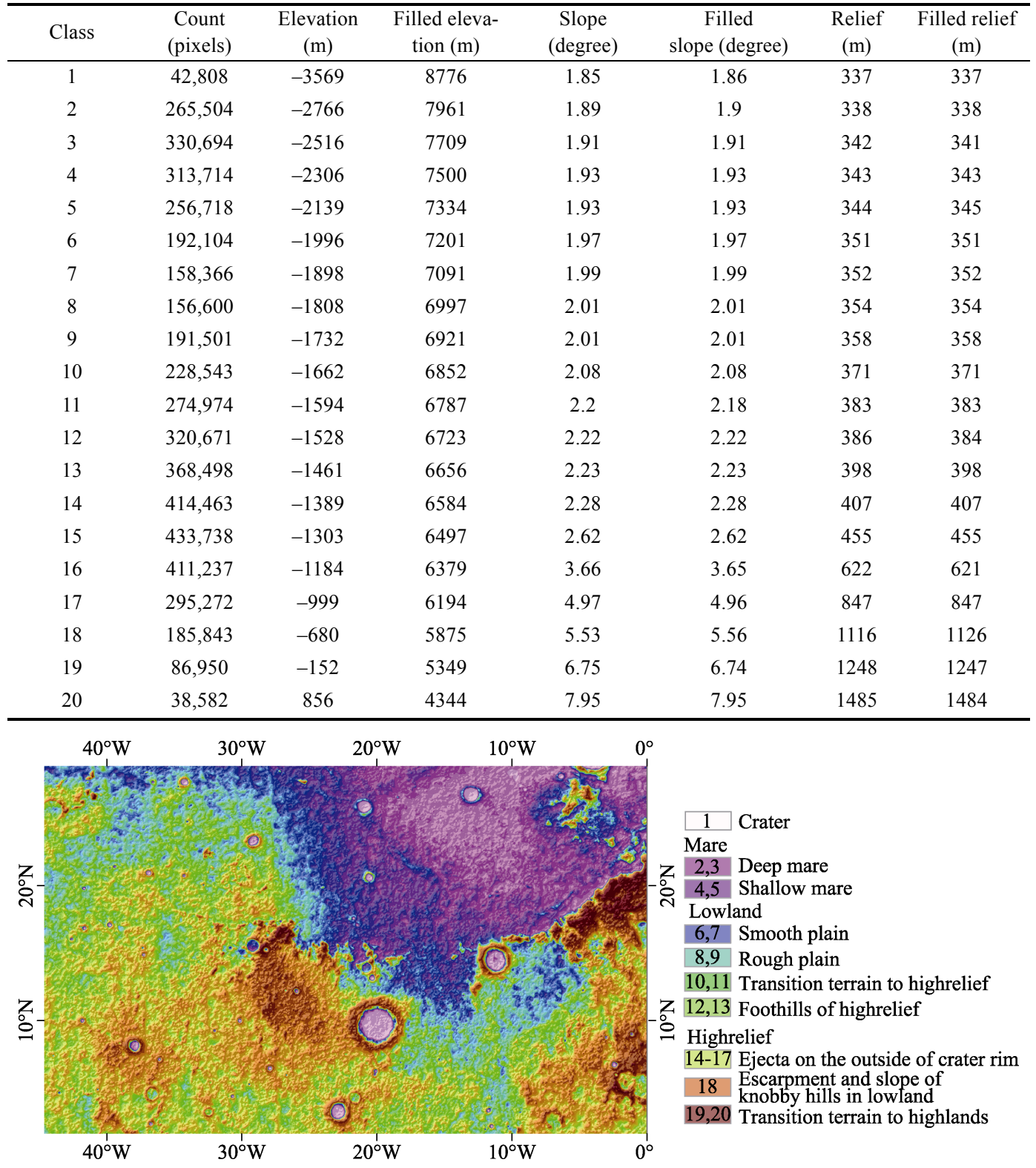

Figure 5 Thematic map showing automatically identified landforms within the LQ-11 test area. The geographic categories corresponding with numbered landform classes are outlined in the legend 


\subsection{LQ-20}

The LQ-20 test area includes a greater diversity of landform units compared to its LQ-8 and LQ-11 counterparts. The topographic attributes for pixels in class 1 within this area are again unique (as above) because they exhibit the smallest values; these pixels are spatially located in large and deep craters and basins, filling their inner spaces, often large, dark, basaltic plains formed by ancient volcanic eruptions. As discussed above, these pixels are indicative of a common landform type which we collectively refer to as 'mare'; results show that $14.81 \%$ of pixels inside the LQ-20 test area can be classified within this group (Table 3 ).

The topographic attributes of pixels in classes $2,3,4,5,6,7,8$, and 9 are similar, with the exception of the signatures of positive values of filled elevation that subdivide this topographic range into eight distinct regions. The pixels in these classes all exhibit small values for all topographic characteristics, with the exception of those in class 6 and class 9; those in class 6 are characterized by higher slope values which perhaps result from steep inner crater walls, while those in class 9 have the highest values for filled slope and relief, perhaps because their crater rims are higher than adjacent lowlands. The pixels in these classes are all identified as the flat floor inside craters, the crater wall, and the crater rim; we collect them all together within a larger group which we refer to here as 'craters'. Results show that $30.27 \%$ of pixels inside the LQ-20 test site can be classified within this group and that they mainly differ from one another in filled elevation values.

The common characteristic of pixels in classes $10,11,12$, and 13 is their low relief. These

Table 3 Average values for landform class morphologic parameters within the LQ-20 test area

\begin{tabular}{|c|c|c|c|c|c|c|c|}
\hline Class & $\begin{array}{c}\text { Count } \\
\text { (pixels) }\end{array}$ & $\begin{array}{c}\text { Elevation } \\
(\mathrm{m})\end{array}$ & $\begin{array}{c}\text { Filled eleva- } \\
\text { tion }(\mathrm{m})\end{array}$ & $\begin{array}{c}\text { Slope } \\
\text { (degree) }\end{array}$ & $\begin{array}{c}\text { Filled } \\
\text { slope (degree) }\end{array}$ & $\begin{array}{c}\text { Relief } \\
(\mathrm{m})\end{array}$ & $\begin{array}{c}\text { Filled relief } \\
(\mathrm{m})\end{array}$ \\
\hline 1 & $13,103,851$ & -5184 & -184 & 6.84 & 6.84 & 272 & 287 \\
\hline 2 & $7,767,995$ & -3749 & 1251 & 10.49 & 10.49 & 432 & 447 \\
\hline 3 & $3,022,547$ & -3047 & 1953 & 10.92 & 10.92 & 460 & 481 \\
\hline 4 & $3,932,609$ & -2584 & 2416 & 11.37 & 11.37 & 478 & 522 \\
\hline 5 & $2,662,286$ & -2132 & 2868 & 12.70 & 12.70 & 540 & 668 \\
\hline 6 & $2,023,806$ & -1779 & 3221 & 14.08 & 14.08 & 603 & 955 \\
\hline 7 & $2,486,296$ & -1439 & 3561 & 13.53 & 13.53 & 581 & 1392 \\
\hline 8 & $2,215,210$ & -1115 & 3885 & 13.47 & 13.44 & 581 & 2684 \\
\hline 9 & $2,665,493$ & -821 & 2558 & 12.43 & 28.63 & 528 & 5942 \\
\hline 10 & $3,546,739$ & -543 & -3558 & 11.34 & 12.90 & 471 & 3494 \\
\hline 11 & $4,014,407$ & -276 & -3276 & 11.39 & 11.35 & 470 & 1489 \\
\hline 12 & $4,133,915$ & -9 & -3009 & 11.75 & 11.75 & 483 & 948 \\
\hline 13 & $4,717,575$ & 277 & -2723 & 12.33 & 12.33 & 509 & 724 \\
\hline 14 & $5,023,863$ & 606 & -2394 & 13.51 & 13.51 & 560 & 666 \\
\hline 15 & $5,161,705$ & 1012 & -1988 & 14.22 & 14.22 & 593 & 646 \\
\hline 16 & $5,667,975$ & 1514 & -1486 & 14.74 & 14.74 & 618 & 651 \\
\hline 17 & $5,556,587$ & 2166 & -834 & 15.04 & 15.04 & 635 & 662 \\
\hline 18 & $5,911,671$ & 3045 & 45 & 15.28 & 15.28 & 650 & 678 \\
\hline 19 & $3,473,170$ & 4427 & 1427 & 16.50 & 16.50 & 707 & 748 \\
\hline 20 & $1,368,136$ & 6032 & 3032 & 16.74 & 16.74 & 722 & 762 \\
\hline
\end{tabular}


pixels are all located spatially below the escarpment and so are collected together in this study into a group that we refer to as 'lowlands'. Results show that $18.55 \%$ of pixels inside the LQ-20 test site can be classified within this group (Figure 6).

Pixels within classes $14,15,16$, and 17 are all located on highlands at high elevations in the vicinity of the escarpment. The pixels within these four classes all share relatively high slope values; as they collectively form an inter-crater plateau located on relatively highlands, we refer to them as 'highrelief' in this study. Results show that $24.20 \%$ of pixels inside the LQ-20 test site can be classified within this group (Table 3).

The topographic attributes of pixels within classes 18,19 , and 20 are all very similar, with the exception of signatures that divide this high elevation range into three regions from the highest (class 20) to the lowest (class 18). The pixels in these classes all share large values for slope and filled attributes, and are located spatially on highlands, above the escarpment, and filling the space between craters. The major difference between these highland classes is their elevation values; results show that $12.16 \%$ of pixels inside the LQ-20 test site can be classified within this group.

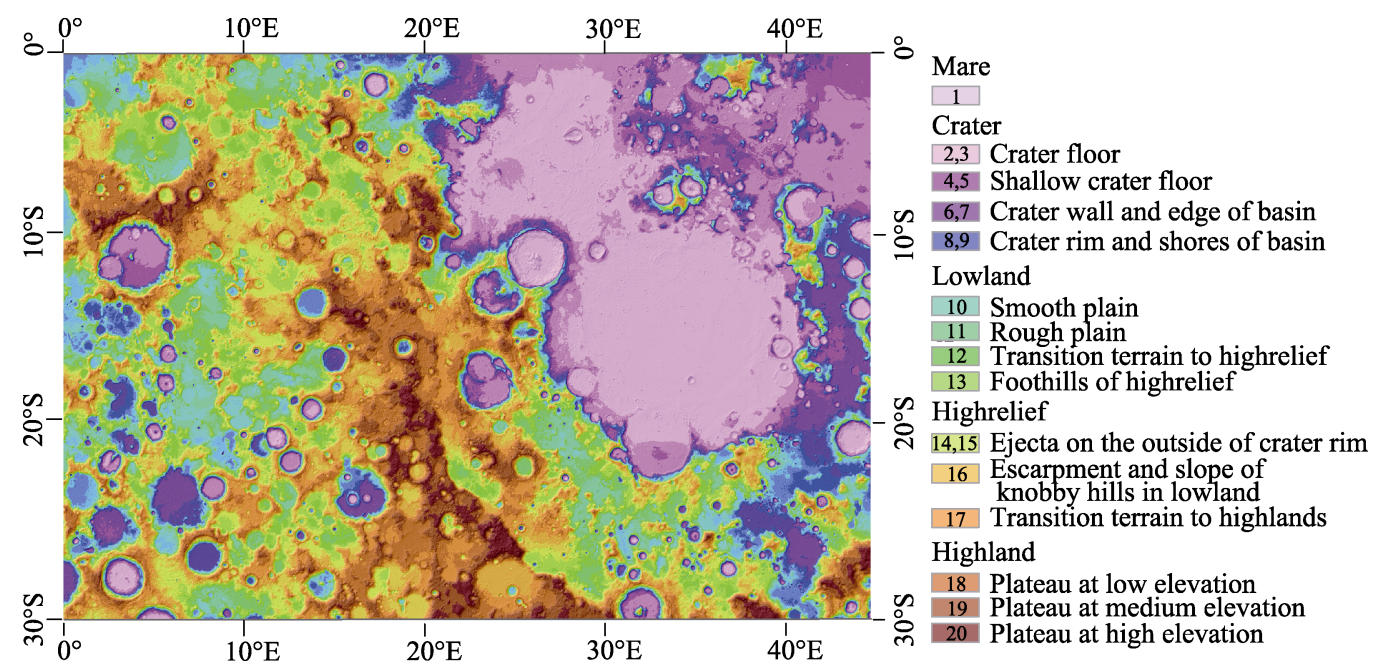

Figure 6 Thematic map to show automatically identified landforms within the LQ-20 test area. The geographic categories corresponding with numbered landform classes are outlined in the legend

\section{Discussion}

The results of this study show significant agreement between the results of automated classification and the reference map for the three test areas. Results reveal slightly higher OA and $\mathrm{K}$ values in area LQ-11 because just a few simple shaped craters with clear rims and a large area of mare plain are present in this region and are easily recognized. In contrast, OA and $\mathrm{K}$ values for area LQ-20 are the lowest because of the relatively complex landform types in this region. Values for UA and PA in the case of crater and mare morphologies are also relatively higher than for other landforms, while UA values for lowlands are also relatively high. The main explanation for these results is that this procedure assumes that craters have steep slopes, while mare plains occur at low elevation, and that lowland and highrelief regions are transitional areas with few distinctive geomorphometric characteristics. However, some old craters that have been heavily eroded can actually be as flat as the surrounding lava 
plains, while highreliefs that have been partly submerged by subsequent lava flows are also problematic as they cause exposed highrelief units to become less topographically distinct. Similarly, lava flows that have moved down steep highland slopes to form blankets pose a different problem because they form plains but will be classified incorrectly as lowlands (Table 4).

Table 4 Error matrix for the best classification result

\begin{tabular}{|c|c|c|c|c|c|}
\hline Test area & Landform & UA\% & $\mathrm{PA} \%$ & $\mathrm{OA} \%$ & K \\
\hline \multirow[t]{5}{*}{ LQ-8 } & Crater & 70.98 & 87.72 & 76.04 & 0.68 \\
\hline & Mare & - & - & & \\
\hline & Lowland & 86.4 & 85.1 & & \\
\hline & Highrelief & 85.41 & 56.79 & & \\
\hline & Highland & 64.24 & 81.72 & & \\
\hline \multirow[t]{5}{*}{ LQ-11 } & Crater & 61.53 & 97.45 & 83.34 & 0.77 \\
\hline & Mare & 85.04 & 82.95 & & \\
\hline & Lowland & 94.97 & 88.35 & & \\
\hline & Highrelief & 81.77 & 71.02 & & \\
\hline & Highland & - & - & & \\
\hline \multirow[t]{5}{*}{ LQ-20 } & Crater & 78.30 & 85.93 & 70.12 & 0.59 \\
\hline & Mare & 92.26 & 69.01 & & \\
\hline & Lowland & 77.54 & 68.62 & & \\
\hline & Highrelief & 53.31 & 67.24 & & \\
\hline & Highland & 76.09 & 87.81 & & \\
\hline
\end{tabular}

Although visual inspection of the topographies shown on the thematic landform map (Figure 6) reveals that our classification is in close agreement overall with expectations, our automatic classification approach has nevertheless misclassified pixels in some regions because of the effects of aggradation (i.e., effusion and deposition) and degradation (i.e., erosion and deformation). Most of these misclassifications, however, occur on low, flat floors inside craters and on lowlands as the similarity measures we calculated between attribute vectors do not correspond to actual landform similarities. For example, infilling will have occurred within basins just up to the level of the lowest pour point around their edges; thus, a crater with undisturbed walls will have been filled to the rim and thus its internal pixels will be classified correctly, while one with a broken wall will be only partially filled and its internal pixels will be misclassified. Results suggest that the degree of misclassification will depend on the severity of the break; ghosted craters that lack clear boundaries will not be filled at all and so these pixels will be severely misclassified compared to other landscape types. To further discuss this issue, we selected three craters for closer examination, labeled $\mathrm{A}\left(3.96^{\circ} \mathrm{E}, 11.4^{\circ} \mathrm{S}\right), \mathrm{B}\left(2.62^{\circ} \mathrm{E}, 11.9^{\circ} \mathrm{S}\right)$, and $\mathrm{C}\left(24.79^{\circ} \mathrm{E}, 28.33^{\circ} \mathrm{S}\right)$. Local views of these craters are shown in Figures $7 \mathrm{a}$ and $7 \mathrm{~b}$; the two panels of this figure illustrate the topography of these features via topographic contours superimposed onto thematic landform maps (Figure 7).

Images show that walls have mostly been damaged by erosion or by the superposition of other craters. The local view in Figure 7a shows that the walls of Crater A are broken in the 8 o'clock direction by Crater B. The pour point level is relatively high in this case, which means that most of the pixels on the crater floor are located beneath it and so are assigned to class 3 and class 4 . However, some pixels on the rim of Crater B that are also on the flat floor of Crater A are also located below the pour point level and so are assigned to class 5 
(a)

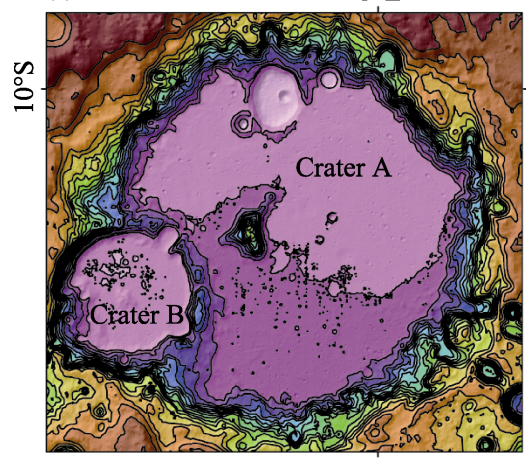

$5^{\circ} \mathrm{E}$ (b)

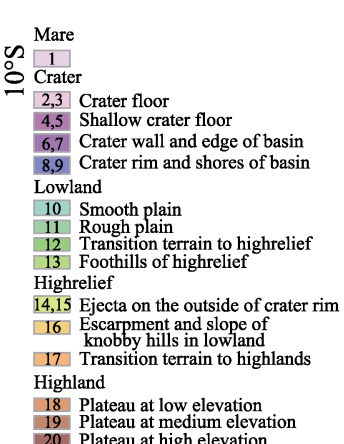
Plateau at medium elevation $25^{\circ} \mathrm{E}$

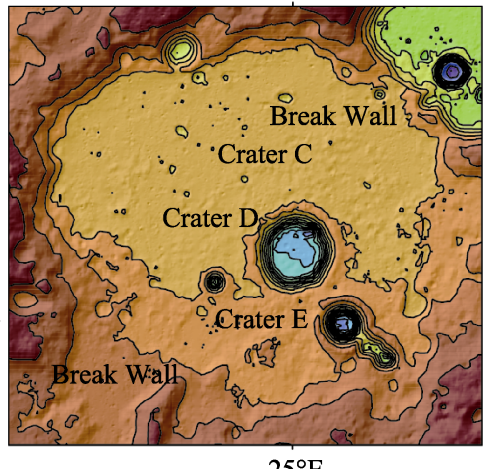

$25^{\circ} \mathrm{E}$

Figure 7 Local views of Crater A and Crater B (a), as well as Crater C, Crater D, and Crater E (b). Topographic contours have been superimposed onto landform maps in both cases; geographic categories corresponding with numbered landform classes are outlined in the legend

and class 6 rather than class 15 and class 16. Similarly, for the same reason, the pixels located on the walls of these craters will also be assigned to class 11 and class 12 rather than to class 15 and class 16 . The small craters that comprise the deep basin within the flat floor of Crater A will also be assigned to class 1 because of their low elevation and maximal fill.

The local view of Crater C (Figure 7b) shows that this feature is also heavily eroded and has shallow walls that are broken in both 1 o'clock and 7 o'clock directions. The pour point level in this case is also very low, resulting in minimal fill; thus, most pixels in the interior of this crater will be assigned to highrelief class 17 and class 18 because they are located at high elevation. Results show that just a handful of deeper points will be classified as lowland and shallow crater floor within Crater D $\left(25.12^{\circ} \mathrm{E}, 28.61^{\circ} \mathrm{S}\right)$ and Crater E $\left(25.49^{\circ} \mathrm{E}\right.$, $\left.29.15^{\circ} \mathrm{S}\right)$.

\section{Conclusions}

This study outlines an ISO cluster unsupervised classification approach for lunar landforms that is based on the hypothesis that each topographic entity on the Moon will be geomorphometrically distinct from the surrounding background. We test this approach using data for three representative lunar areas, LQ-8, LQ-11, and LQ-20. Numerous existing automated extraction approaches aim to identify and extract discrete landforms, including impact craters, valley networks, and other elements, by emphasizing their particular surface shapes; fewer, generically applicable, methodologies are available that evaluate the geometry of continuous surfaces (e.g., the whole lunar surface) and that are founded on statistical characterization. In this study, we have shown that our methodology is applicable by utilizing techniques drawn from the fields of data mining and artificial intelligence and applying them to planetary geomorphology. Thus, automated recognition of landforms can be achieved using our method at the local level of constituent pixels; each pixel in a continuous topography represented by a DEM is automatically classified by our ISO cluster unsupervised classification into one of 20 undefined landform types using the terrain parameters, elevation, filled elevation, slope, filled slope, relief amplitude, and filled relief amplitude. We chose an ISO cluster approach to generate initial groupings because of speed; ISO cluster processing of each DEM took approximately five minutes on a $2.50 \mathrm{GHz}$ Core i3 machine for each test 
area.

Our results show that while elevation appears to be critical in recognizing highlands, filled elevation is of greater utility in distinguishing craters and mare plains. Subsequent to separating obvious landforms from other topographic features, our procedure then automatically adjusts the sensitivity of its criteria to accommodate subtler surface forms such as lowland and highrelief using filled slope and relief amplitude. In order to ensure statistically robust class definitions, thresholds for subdividing images are arbitrarily set as the mean values of frequency distributions and the signatures of input parameters. We quantitatively evaluated our approach using a series of confusion matrices and achieved overall accuracies as high as $83.34 \%$ and $\mathrm{K}$ values as high as 0.77 . Our method represents a step forward because it is a reproducible and directly transferable approach to map lunar landforms; this technique can be performed easily using a GIS mapping platform, effortlessly edited, and incorporated into a general mapping procedure along with other landforms.

Automated classification generally results in less focused, more general purpose, thematic maps that incorporate broadly defined semantic meanings for landform classes. This reflects the unsupervised nature of the classifier; no landforms are defined beforehand and their meanings are established afterwards. Thus, the only available control over the emphasis placed on a landform is through choice of topographic attributes. In contrast, artificial landform classifications apply narrowly defined semantic definitions before mapping; thus, unsupervised landform classification facilitates automated searches for unexpected landscape features, while use of an automated classifier enables the quantitative determination of topographic similarities between different sites. Furthermore, the use of automated classification at the pixel level can delineate landscape features that exhibit detailed geomorphologic characteristics; lunar impact craters, for example, can be conveniently counted and described on the basis of constituent elements such as the crater rim, crater wall, ejecta, and central peak. We also tested the behavior of our classification system in this study, running it many times over the same dataset and generating identical results in each case. Results show that our classification system can accurately generate reproducible outputs, although further research will be required to establish optimal algorithm parameter values in a planetary context given the availability of high quality datasets, as well as to generate more complete terrestrial and planetary landform maps.

\section{Acknowledgments}

The LOLA DEM data and lunar geologic map used in this study were provided by the USGS. We also thank Professor Tomasz F. Stepinski for his considerable work on the recognition approach used on Mars; his contribution significantly influenced this paper.

\section{References}

Adediran A O, Parcharidis I, Poscolieri M et al., 2004. Computer-assisted discrimination of morphological units on north-central Crete (Greece) by applying multivariate statistics to local relief gradients. Geomorphology, 58: 357-370. doi: 10.1016/j.geomorph.2003.07.024.

Bolongaro-Crevenna A, Torres-Rodriguez V, Sorani V et al., 2005. Geomorphometric analysis for characterizing landforms in Morelos State, Mexico. Geomorphology, 67(3): 407-422. doi: 10.1016/j.geomorph.2004.11.007.

Bue B D, Stepinski T F, 2006. Machine detection of Martian craters from digital topography. In: 37th Annual Lunar and Planetary Science Conference, 37: 1178. 
Burrough P A, McDonnell R A, 2011. Principles of Geographical Information Systems (Vol. 19988). Oxford: Oxford University Press.

Burrough P A, Gaans P F M V, Macmillan R A, 2000. High-resolution landform classification using fuzzy k-means. Fuzzy Sets and System, 113(1): 37-52. doi: 10.1016/S0165-0114(99)00011-1.

Butle D R, Walsh S J, 1998. The application of remote sensing and geographic information systems in the study of geomorphology: An introduction. Geomorphology, 21(3): 179-181. doi: 10.1016/S0169-555X(97)00056-1.

Cohen J, 1960. A coefficient of agreement for nominal scales. Educational and Psychological Measurement, 20(1): 37-46. doi: 10.1177/001316446002000104.

Dehn M, Gärtner H, Dikau R, 2001. Principles of semantic modeling of landform structures. Computer Geoscience, 27: 1005-1010. doi: 10.1016/S0098-3004(00)00138-2.

Drăguţ L, Blaschke T, 2006. Automated classification of landform elements using object-based image analysis. Geomorphology, 81(3): 330-344. doi: 10.1016/j.geomorph.2006.04.013.

Ehlers M, Janowsky R, Gaehler M, 2002. New remote sensing concepts for environmental monitoring. In: International Society for Optics and Photonics. International Symposium on Remote Sensing, 1-12.

Florinsky I V, 1998. Accuracy of local topographic variables derived from digital elevation models. International Journal of Geographical Information Science, 12(1): 47-62. doi: 10.1080/136588198242003.

Fortezzo C M, Hare T M, 2013. Completed digital renovation of the 1:5,000,000 lunar geologic map series. Lunar and Planetary Science Conference, Vol. 44.

Gaddis L R, Skinner J A J, Hare T et al., 2006. The lunar geologic mapping program and status of Copernicus quadrangle mapping. In: 37th Annual Lunar and Planetary Science Conference, Vol. 37, p.2135.

Giles P T, Franklin S E, 1998. An automated approach to the classification of the slope units using digital data.Geomorphology, 21(3): 251-264. doi: 10.1016/S0169-555X(97)00064-0.

Guth P L, 1995. Slope and aspect calculations on gridded digital elevation models: Examples from a geomorphometric toolbox for personal computers. Zeitschrift fur Geomorphologie Supplementband, 101: 31-52.

Hengl T, Rossiter D G, 2003. Supervised landform classification to enhance and replace photo-interpretation in semi-detailed soil survey. Soil Science Society of America Journal, 67: 1810-1822. doi: 10.2136/sssaj2003.1810 .

Hodgson M E, 1998. Comparison of angles from surface slope/aspect algorithms. Cartography and Geographic Information Systems, 25(3): 173-185. doi: 10.1559/152304098782383106.

Iwahashi J, Pike R J, 2007. Automated classifications of topography from DEMs by an unsupervised nested-means algorithm and a three-part geometric signature. Geomorphology, 86: 409-440. doi: 10.1016/j.geomorph.2006.09.012.

Jenks G F, Caspall F C, 1971. Error on choroplethic maps: Definition, measurement, reduction. Annals of the Association of American Geographers, 61(2): 217-244. doi: 10.1111/j.1467-8306.1971.tb00779.x.

Jones K H, 1998. A comparison of algorithms used to compute hill slope as a property of the DEM. Computer Geoscience, 24: 315-324. doi: 10.1016/S0098-3004(98)00032-6.

Kohonen T, 1982. Self-organized formation of topologically correct feature maps. Biological Cybernetics, 43(1): 59-69. doi: 10.1016/S0925-2312(98)00030-7.

Lewis H G, Brown M, 2001. A generalized confusion matrix for assessing area estimates from remotely sensed data. International Journal of Remote Sensing, 22(16): 3223-3235. doi: 10.1080/01431160152558332.

Miliaresis G C, 2001. Extraction of bajadas from digital elevation models and satellite imagery. Computer Geoscience, 27(10): 1157-1167. doi: 10.1016/S0098-3004(01)00032-2.

O'Callaghan J F, Mark D M, 1984. The extraction of drainage networks from digital elevation data. Computer Vision, Graphics, and Image Processing, 28(3): 323-344. doi: 10.1016/S0734-189X(84)80011-0.

Prima O D A, Echigo A, Yokoyama R et al., 2006.Supervised landform classification of Northeast Honshu from DEM-derived thematic maps. Geomorphology, 78: 373-386. doi: 10.1016/j.geomorph.2006.02.005.

Smith D E, Zuber M T, Jackson G B et al., 2010. The lunar orbiter laser altimeter investigation on the lunar reconnaissance orbiter mission. Space Science Review, 150(1-4): 209-241. doi: 10.1007/s11214-009-9512-y.

Stepinski T F, Collier M L, 2004. Extraction of Martian valley networks from digital topography. Journal of Geophysical Research, Planets, 109(E11): 179-204. doi: 10.1029/2004JE002269.

Stepinski T F, Vilalta R, 2005. Digital topography models for Martian surfaces. IEEE Geoscience and Remote Sensing Letters, 2(3): 260-264. doi: 10.1109/LGRS.2005.848509.

Tarboton D G, Bras R L, Rodriguez-Iturbe I, 1989. The analysis of river basins and channel networks using digital terrain data. Technical Report No. 326, Ralf M. Cambridge: Parsons Laboratory, MIT.

Wang J, Cheng W M, Zhou C H, 2015. A Chang'E global catalog of lunar impact craters. Planet Space Science, 112: 42-45. doi: 10.1016/j.pss.2015.04.012.

Wessel P, Smith W H, 2001. The Generic Mapping Tools. http://gmt.soest.hawaii.edu. 